\title{
DETERMINATION OF MECHANICAL PROPERTIES OF REPAIR MORTARS USING IN SITU METHODS UNDER DIFFERENT CURINGS
}

\author{
Ali Saberi Varzaneh ${ }^{1}$ \\ ali.saberi@edu.ikiu.ac.ir \\ Mahmoud Naderi \\ profmahmoodnaderi@eng.ikiu.ac.ir \\ ${ }^{1}$ Department of Civil Engineering \\ Imam Khomeini International University \\ Qazvin, Iran
}

\begin{abstract}
Considering the differences between environmental conditions of concrete structures and laboratory conditions, it is important to determine the parameters of the materials at the site of the structure. One of these materials is cement-based repair mortars due to the damage of concrete structures that may arise due to chemical or physical factors, these structures are required to be repaired. For this reason, in this paper, to determine the strength of repair mortars of different ages and under different Curing, Situ methods "Friction-Transfer" and "Pull-off" were used and the relationships between the Flexural Compressive, Tensile and readings obtained from the above methods on cementations mortars are presented. Experiments were performed on mortars at ages 3, 7, 28, 42 and 90 days under the conditions of "waterlogging", "Curing Agent" and "releasing in the outdoor". The results show the high impact of the process on the Flexural Compressive, Tensile of the repair mortars and the results of the "Friction-Transfer" and "Pull-off" methods. Also, a high correlation coefficient was obtained between the mechanical properties of the mortars and the results of the above tests; it is possible to measure the mechanical properties of repair mortars in situ with high confidence and in situ.
\end{abstract}

Keywords: flexural strength, compressive strength, tensile strength, processing, "Friction-Transfer", "Pull-off", repair mortar.

DOI: $10.21303 / 2461-4262.2020 .001190$

\section{Introduction}

Since the laboratory methods of determining the mechanical properties of mortars mainly control the quality of the materials used in their preparation and do not provide a proper assessment of the process of obtaining mortar strength at the site, it is important to conduct tests to evaluate the strength of mortars. The in situ methods of determining the mechanical properties of mortars are used in such cases as the process of obtaining strength, evaluating existing strength, and so on. There are many methods to determine the strength of concrete and mortar in situ that are generally divided into three categories: "destructive", "semi-destructive" and "non-destructive". Destructive methods include loading the fragment into the structure or the fragment itself, or core drilling part of the fragment and testing it in the laboratory under standard conditions [1]. But these methods have disadvantages these include high cost, significant damage to the structure, limited repeatability and usually the closure of the operation of the structure during testing. Also, the results of the tests on the obtained core drilling are less than the actual compressive strength [2]; also, some parts of the structure may not have core drilling. The "pull out" method is another method [3] that falls into the category of destructive methods and causes damage to the concrete element.

Therefore, the tendency to carry out in situ experiments in the form of non-destructive or semi-destructive methods is increasing day by day. Non-destructive methods such as ultrasonic [4] testing and the Schmidt [5] test can measure some properties of materials without the presence of destructive strengths. Semi-destructive methods can provide valuable results in strength in situ materials by causing minor damage. In-situ methods include "Friction-Transfer" [6] and "Pull-off" [7] tests. In the "Friction-Transfer" method, a core is first created by a scoring machine. Then the metal device is fixed to the partial core and with a normal Torque Meter, a torsional anchor is inserted to break it down. Previous research has also used the "Friction-Transfer" test to determine the com- 
pressive strength of rock and concrete and a high correlation coefficient between the results of the "Friction-Transfer" test and the compressive strength of the stone and concrete [6,8], in the "Pulloff" test to determine the strength of mortar, a $5 \mathrm{~cm}$ diameter metal cylinder is first adhered to the test site using epoxy resin adhesive. Then, using a "Pull-off" device, the tensile strength is applied to the cylinder to separate it from the concrete surface.

Cement mortars have many uses including use as repair material on parts of concrete elements damaged by various chemical or physical conditions or use them inside masonry buildings with brick walls. Therefore, it is necessary to know the exact characteristics of mortars, including compressive, tensile and flexural strength. A lot of laboratory research has been done on the mechanical properties of mortars. In a study on in vitro evaluation the effect of mixing ratios on the compressive strength of cementations mortars was determined. Different ratios of water to cement and sand to cement have a great effect on the compressive strength of mortars as the water-cement ratio decreases, the compressive strength of the mortar increases. Also, at low water to cement ratios, the impact of sand to cement ratio has a greater impact on the compressive strength of the mortar [9]. In addition to compressive strength, it is important to determine the tensile strength of mortars because mortars are generally not strength with concrete as opposed to concrete and in cases such as facade and rock where tensile strengths are applied, their tensile strength must be determined. In studies on tensile strength of mortars including water to cement ratio of 0.4 to 0.65 was determined the tensile and compressive strength of cement sand mortar is inversely proportional to the increase in water to cement ratio. In this study, tensile strengths of mortars were about $7 \%$ of compressive strength [10]. The high water-cement ratio also results in porosity inside the mortar, which reduces the mortar strength. In the research on the effect of water to cement ratio on mortar porosity it was found that increasing the water to cement ratio in cement mortar from 0.45 to 0.6 increases the porosity of the mortar by 1.5 times [11].

In order to increase the mortar strength gain over time, the Curing should be used. The process completes the cement hydration process over time. In the first few days after the mortar is made, if the temperature and humidity are favorable, the hydration will be relatively rapid, but maintaining water inside the mortar during this time is important and water evaporation should be prevented or substantially reduced. The amount of temperature and duration of moisture treatment are keys to discussing the Curing because the hydration process, as it relates to the quality and quantity of cementations materials in the mixture, is not related to the temperature and humidity inside the mixture [12]. Generally, the processing time for aggregates made with conventional Portland cement is 7 days, which is, however, longer for late cements [13].

In this paper, using two types of mortar with different water-cement ratio, their flexural, tensile and compressive strength were determined in vitro. Then, using the methods of "Friction-Transfer" and "Pull-off", the relationship between the readings obtained from the mentioned methods and the compressive, tensile and flexural strengths was obtained. Experiments were performed on mortars at 3, 7, 28, 42 and 90 days of age. There were also three different processes, including "waterlogging", "Curing Agent" and "releasing in the outdoor". The results show a high correlation between the compressive, tensile and flexural strengths of the cementations sand mortar with the readings obtained from the "Friction-Transfer" and "Pull-off" tests, as a result, these methods can be used as an in situ method for determining the strength of cementations sand mortars.

One of the major innovations of this paper is the use of in situ (friction transfer) method to evaluate the resistance of cementations repair mortars of different ages. Due to its unique test performance (friction transfer) that makes this test applicable to any laboratory and environmental conditions, this test can be used to determine the resistance of the laboratory and the location of consumables in the road, building and construction industries, with the aim of quality control and research studies. Due to the damage caused by the test (friction transfer) which is very superficial and minor, This test falls into the category of semi-destructive tests, or more precisely, with minor failures. Because in this test, failure occurs within the target object itself Therefore, its results are more reliable than surface hardness tests or tests that indirectly determine the strength of the materials. The equipment used in the test (friction transfer) is very simple, inexpensive and acces- 
sible. This test is highly accurate and can be performed under all environmental conditions (dry, wet, underwater and under any temperature). The "friction transfer" test can be done in a very short time (about 10 minutes) and does not require skilled people. Since the acceptability of each new test requires that the results of that test be compared with the corresponding results obtained from standard and well-known common tests, therefore, in this paper, this comparison is made and the relationships between the resistances of applying "friction transfer", "pull-off" tests, standard compressive, flexural and tensile tests of repair mortars of different ages and under different machining are presented.

\section{Laboratory activities}

\section{1. Consumer materials}

The cement used for making mortar is Type 2 with a density of $3007 \mathrm{~kg} / \mathrm{m}^{3}$. Table 1 shows the specifications of Type 2 cement.

Table 1

Chemical Properties of Type 2 Cement

\begin{tabular}{ccccccccccc}
\hline Chemical Properties & $\mathrm{Fe}_{2} \mathbf{O}_{3}$ & $\mathrm{SiO}_{2}$ & $\mathrm{Al}_{2} \mathbf{O}_{3}$ & $\mathbf{C a O}$ & $\mathrm{Na}_{2} \mathbf{O}$ & $\mathbf{K}_{2} \mathbf{O}$ & $\mathbf{S O}_{3}$ & $\mathbf{M g O}$ & $\mathrm{LOI}$ & $\mathrm{C}_{3} \mathbf{A}$ \\
\hline Weight (\%) & 3.84 & 21.05 & 4.81 & 62.44 & 0.74 & 0.26 & 1.99 & 3.20 & 1.89 & 6.25
\end{tabular}

The sand with a maximum size of $4.75 \mathrm{~mm}$ was used and its grading was performed according to ASTM C136 standard [14]. The rate of sand uptake was $3.2 \%$ based on ASTM C127 [15, 16]. The density of sand in the saturated state is $2510 \mathrm{~kg} / \mathrm{m}^{3}$. The graph of the sand grains is shown in Fig. 1.

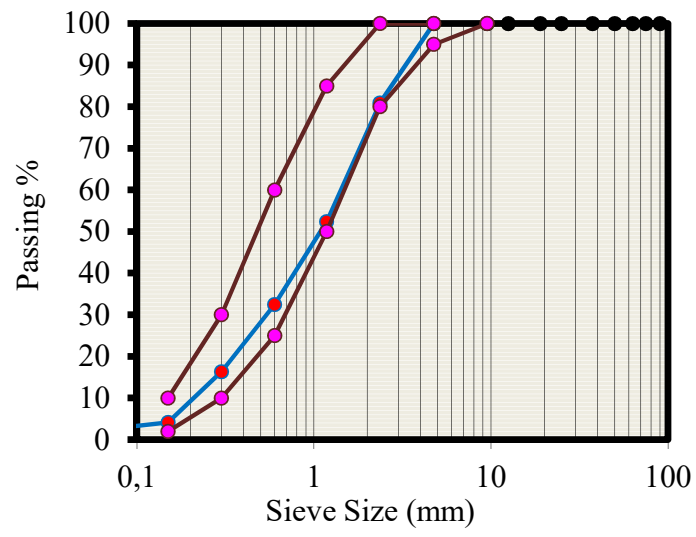

Fig. 1. Aggregates grain diagram

The two-component adhesives used are epoxy resins with one-volume volumetric composition and polyolefin-acting materials. The mechanical properties of epoxy resin adhesive are shown in Table 2.

Table 2

Mechanical properties of two-component epoxy resin adhesive

\begin{tabular}{ccccccc}
\hline $\begin{array}{c}\text { Modulus of } \\
\text { elasticity }\end{array}$ & $\begin{array}{c}\text { 7-day compressive } \\
\text { strength }\end{array}$ & Shear strength & \multicolumn{2}{c}{ Reception time } & \multicolumn{2}{c}{ Processing time } \\
\cline { 4 - 7 } & & $\mathbf{3 5}^{\circ} \mathbf{C}$ & $\mathbf{2 5}^{\circ} \mathbf{C}$ & $\mathbf{3 5}^{\circ} \mathbf{C}$ & $\mathbf{2 5}^{\circ} \mathbf{C}$ \\
\hline $12750 \mathrm{MPa}$ & $70 \mathrm{MPa}$ & $15 \mathrm{MPa}$ & $4 \mathrm{~h}$ & $10 \mathrm{~h}$ & $45 \mathrm{~min}$ & $90 \mathrm{~min}$
\end{tabular}

\section{2. Repair mortar}

Cement to sand ratio of 1:2 was used to make repair mortars. The ratio of water to cement is 0.5 in one mortar and 0.4 in the other (Table 3). 
Table 3

Mortars specification

\begin{tabular}{ccc}
\hline Abbreviation & Cement to sand Ratio & Water to cement ratio \\
\hline M1 & $1: 2$ & 0.4 \\
M2 & $1: 2$ & 0.5
\end{tabular}

Examples of tests required for compressive, flexural, tensile, "Friction-Transfer" and "Pulloff" post-fabrication tests in "waterlogging", "Curing Agent" and "releasing in the outdoor" were left. They were then excised and tested at 3, 7, 28, 42 and 90 days of age. A total of 180 samples were tested for compressive strength, 90 for flexural strength, and 90 for tensile strength, 90 for Friction-Transfer test and 90 for Pull-off test.

\section{Laboratory Methods}

\section{1. Friction-Transfer method}

To determine the strength of the concrete by "Friction-Transfer" test, first with a core drilling machine, create a partial core $25 \mathrm{~mm}$ high in repair mortar, then fix the "Friction-Transfer" device on it. It is inserted into the torsional anchor by a conventional torsion gauge to cause the core to fail (Fig. 2).

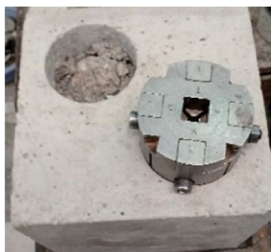

$a$

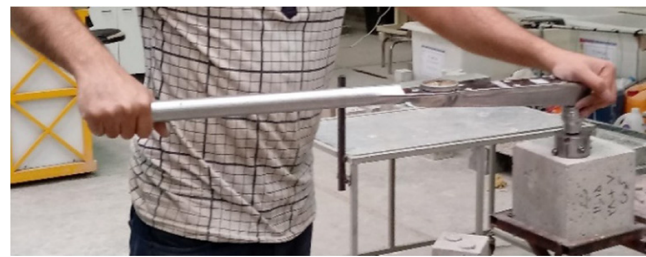

Fig. 2. "Friction-Transfer" test: $a$ - fixing the metal piece on the specimen; $b-$ applying the torsional anchor with the Torque Mete

Considering the final torsional anchor (fracture) and using the relationship between shear stress and torsional anchor (1), let's calculate the shear strength of adhesion of the repair layer to the concrete substrate $(\tau)$.

$$
\tau=\frac{T c}{J}
$$

where $r$ is the radius of the core and $J$ is the second polar moment of the surface.

Due to the damage caused by the Friction-Transfer test, which is very minor, this test falls into the "minor damage" test. The amount of damage caused by this test is $6 \mathrm{~cm}$ in diameter and $2.5 \mathrm{~cm}$ in depth. In order to perform the "Friction-Transfer" test, cubic specimens of $15 \mathrm{~cm}$ were first prepared and subjected to different Curings and then tested at different ages.

\section{Pull-off Method}

In the "Pull-off" test to determine the strength of mortar, a $5 \mathrm{~cm}$ diameter metal cylinder is first adhered to the test site using epoxy resin adhesive. Then, using the "Pull-off" device, the tensile strength is applied to the cylinder to separate it from the concrete surface (Fig. 3). According to eq. (2), the strength value obtained by the "Pull-off" method is obtained by dividing the tensile strength applied to the cylindrical surface.

$$
\sigma_{T}=\frac{P}{A},
$$

where $P$ is the tensile strength and $A$ is the tangency area. 


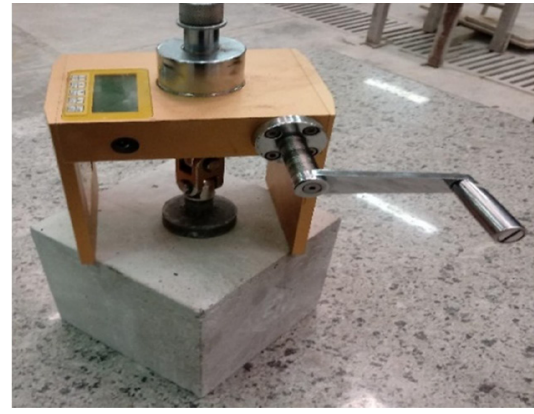

$a$

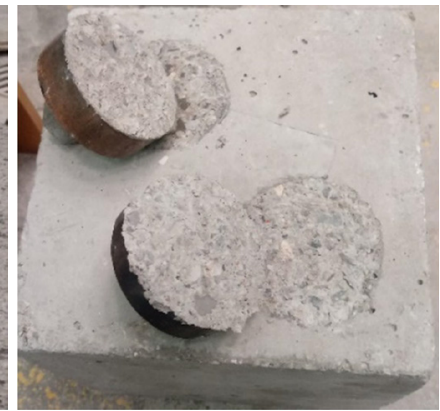

$b$

Fig. 3. "Pull-off" test: $a$ - applying the tensile strength to the cylinder; $b$ - test result

To perform the "Pull-off" test, cubic specimens of $15 \mathrm{~cm}$ were first prepared and subjected to different Curings and then tested at different ages.

\section{Flexural strength measurement}

Prismatic specimens of $4 \times 4 \times 16 \mathrm{~cm}$ were made to determine the flexural strength of mortars in accordance with ASTM C348 [17]. For each experiment, 3 specimens were prepared and tested according to Fig. 4.

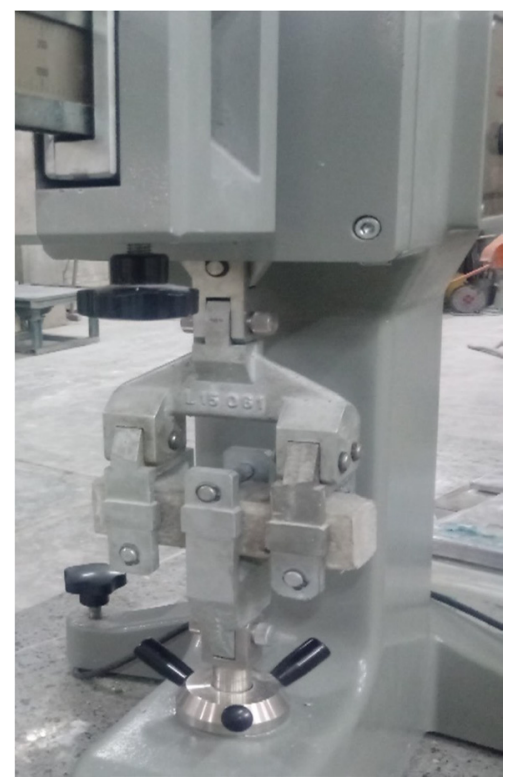

Fig. 4. Flexural strength of mortar

Equation 3 is used to obtain the flexural strength of the mortar.

$$
S_{f}=0.0028 P
$$

where $P$ is the maximum strength applied to the device in Newton.

\section{1. Tensile strength measurement}

Tensile strength of mortars was determined by making briquette specimens using ASTM C190 [18] standard, an average of 3 samples were considered for measuring tensile strength. According to Fig. 5 by the apparatus, the specimens were subjected to tensile loads to failure. The amount of tensile strength of mortars is obtained by dividing the applied tensile strength by the area of the fractured part, Fig. 5. 


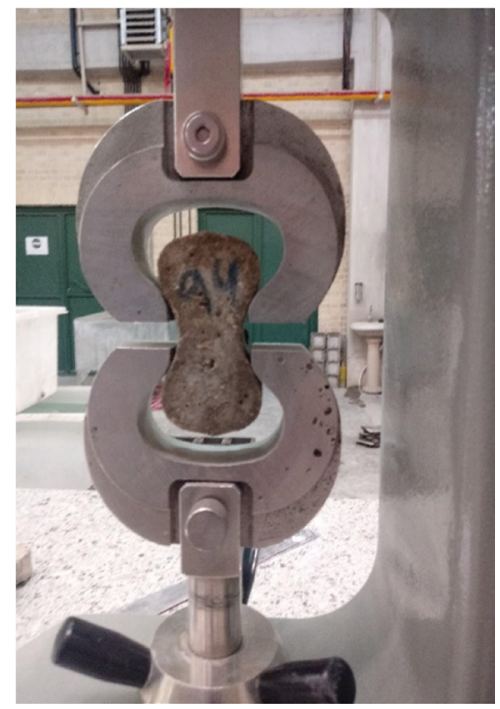

Fig. 5. Apply tensile strength to specimens

\section{2. Measurement of the compressive strength}

Determination of the compressive strength of the applied mortars was performed using ASTM C109 [19] standard and for each mortar type, $650 \mathrm{~mm}$ cubic specimens were made, their compressive strengths of different ages were measured and the mean results of 6 specimens were considered as compressive strengths (Fig. 6).

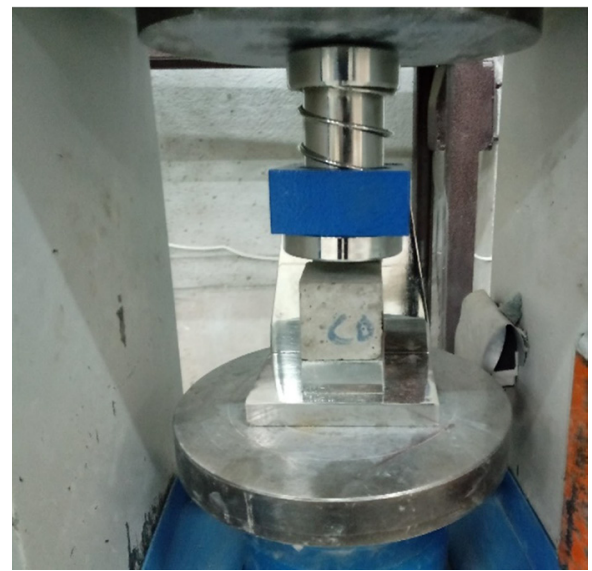

Fig. 6. Compressive strength of mortar

\section{Results and their analysis}

\section{1. Compressive strength of repair mortar}

In this section, the compressive strength of repair mortars at ages 3, 7, 28, 42 and 90 days, which were subjected to in-water treatments, with release and release materials, were tested. The results of the "Friction-Transfer" and "Pull-off" tests with M1 mortar compressive strength are shown in Table 4. In this table the results of compressive strength are the mean of 6 samples and the results of "Friction-Transfer" and "Pull-off" methods are averaged of 3 samples.

According to Table 4 for M1 mortar, it is observed that the compressive strength of mortars curing in water and with curing agent is higher than those released in open space due to the completion of the cement hydration process inside the mortar to prevent It is the removal of moisture inside the mortar. The hydration of Portland cement involves the reaction of unhydrated calcium silicate and the aluminate phase with water. For the mortars cured with water and the curing agent with the mortars released in the open space, the 90-day compressive strength was 1.72 and 1.41, respectively. The same trend was observed for the other ages as the values of 3, 7,28 and 42 days for 
water cured samples were 1.77, 1.64, 1.67, and 1.69 times, respectively. The compressive strength of the mortar is released in the open space. For the cured specimens with the same material, the compressive strength of the specimens cured with the open space specimens was $1.45,1.46,1.44$ and 1.39 , respectively. The results of the "Friction-Transfer" and "Pull-off" tests on the cured samples also have an increasing trend over time, so that the strength obtained by the "Friction-Transfer" method at 90 days compared to 3 days In the three procedures mentioned, they are 2.36, 2.4 and 2.46 , respectively. The 90 -day to 3 -day strength ratio is $2.57,2.52$, and 2.41 , respectively, for the "Pull-off" test.

\section{Table 4}

Results of compressive strength test, "Friction-Transfer" and "Pull-off" on M1 mortar (MPa)

\begin{tabular}{|c|c|c|c|c|c|c|c|c|c|c|c|c|c|c|c|}
\hline \multirow[b]{2}{*}{$\begin{array}{c}\text { Test } \\
\text { Method }\end{array}$} & \multicolumn{3}{|c|}{3 days } & \multicolumn{3}{|c|}{7 days } & \multicolumn{3}{|c|}{28 days } & \multicolumn{3}{|c|}{42 days } & \multicolumn{3}{|c|}{90 days } \\
\hline & 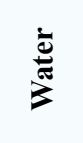 & 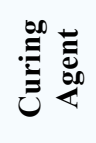 & $\frac{n}{0}$ & हัँ & $\stackrel{0}{\Xi}$ & $\frac{0}{0}$ & $\frac{\grave{\Xi}}{\bar{*}}$ & 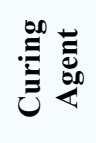 & 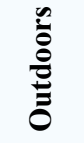 & $\frac{\grave{\Xi}}{\pi}$ & 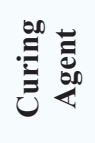 & $\frac{0}{0}$ & 这 & 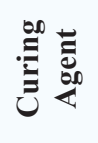 & 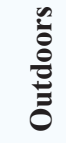 \\
\hline $\begin{array}{l}\text { Compressive } \\
\text { strength }\end{array}$ & 28.5 & 23.4 & 16.1 & 40.6 & 36.1 & 24.8 & 56.2 & 48.6 & 33.7 & 61 & 50.4 & 36.2 & 64.7 & 53.1 & 37.6 \\
\hline "Friction transfer" & 2.72 & 2.14 & 1.62 & 4.09 & 3.45 & 2.61 & 5.29 & 4.38 & 3.37 & 5.89 & 4.8 & 3.75 & 6.34 & 5.13 & 3.98 \\
\hline "Pull off" & 1.42 & 1.24 & 0.89 & 2.08 & 1.87 & 1.37 & 2.65 & 2.31 & 1.72 & 3.28 & 2.78 & 2.05 & 3.65 & 3.13 & 2.15 \\
\hline
\end{tabular}

The results of the "Friction-Transfer" and "Pull-off" tests with M2 mortar compressive strength are shown in Table 5. In this table the results of compressive strength are the mean of 6 samples and the results of "Friction-Transfer" and "Pull-off" methods are averaged of 3 samples.

Table 5

Results of compressive strength test, "Friction-Transfer" and "Pull-off" on M2 mortar (MPa)

\begin{tabular}{|c|c|c|c|c|c|c|c|c|c|c|c|c|c|c|c|}
\hline \multirow[b]{2}{*}{$\begin{array}{c}\text { Test } \\
\text { Method }\end{array}$} & \multicolumn{3}{|c|}{3 days } & \multicolumn{3}{|c|}{7 days } & \multicolumn{3}{|c|}{28 days } & \multicolumn{3}{|c|}{42 days } & \multicolumn{3}{|c|}{90 days } \\
\hline & $\frac{\bar{\Phi}}{\bar{n}}$ & $\stackrel{0}{\Xi}$ & 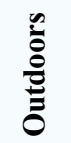 & $\sum^{\stackrel{ \pm}{*}}$ & $\stackrel{\infty}{\Xi}$ & 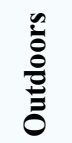 & $\frac{\grave{j}}{\hbar+}$ & $\stackrel{0}{\Xi}$ & 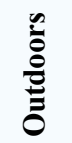 & לे & 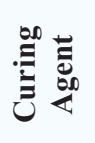 & 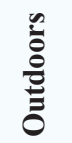 & לे & 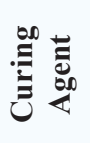 & $\frac{n}{0}$ \\
\hline $\begin{array}{l}\text { Compressive } \\
\text { strength }\end{array}$ & 23.3 & 19.2 & 13.2 & 34.1 & 30.2 & 20.9 & 47.6 & 40.9 & 28.6 & 51.2 & 43 & 30.9 & 54.4 & 45.1 & 32.1 \\
\hline "Friction transfer" & 2.36 & 1.89 & 1.44 & 3.61 & 3.05 & 2.31 & 4.69 & 3.84 & 2.97 & 5.19 & 4.2 & 3.35 & 5.64 & 4.56 & 3.55 \\
\hline "Pull off" & 1.22 & 1.06 & 0.76 & 1.77 & 1.61 & 1.19 & 2.29 & 1.99 & 1.49 & 2.82 & 2.4 & 1.76 & 3.17 & 2.74 & 1.88 \\
\hline
\end{tabular}

According to Table 5 for M2 mortar, it is observed that the compressive strength of mortars processed with water is higher than that of mortars released in outdoor. For the mortars processed with water and the materials processed with the mortars released in the outdoor, the 90-day compressive strength was 1.69 and 1.4 times, respectively. The same is true for other ages, such a way that for water processed samples, The values of 3, 7, 28 and 42 days compressive strength were 1.77, $1.63,1.66$ and 1.65 times the compressive strength of the mortar released in outdoor, respectively. Also for samples processed with handling materials, at the above ages, the amount of increase in compressive strength compared to the samples released in the outdoor was 1.45, 1.44, 1.43 and 1.39, respectively. The results of the "Friction-Transfer" and "Pull-off" tests on the processed specimens have also increased over time. So that the strength obtained by the "Friction-Transfer" method at 90 days compared to the 3 days at the three Curings mentioned is $2.39,2.41$ and 2.47, respectively. For the "Pull-off" test, the 90-day to 3-day strength ratio is 2.6, 2.58, and 2.47, respectively.

The results of the compressive strength of both mortars show that the processing has increased the compressive strength. The results of the compressive strength of both mortars show that the processing has increased the compressive strength. The practical application is because 
cement hydration only occurs in hairy pores filled with water. Therefore, water loss due to evaporation should be avoided to complete the hydration process, which can be achieved by application of process. A study on mortar compressive strength found that 28-day mortar compressive strength was about $37 \%$ higher than its 7-day compressive strength [20]. Also, in another study for mortars processed in water, the 28-day compressive strength was $54 \%$ higher than the 7 -day compressive strength [21]. In this study, the 28-day compressive strength of water-processed mortar was about $40 \%$ higher than the 7-day compressive strength of the sample.

Fig. 7 shows the correlation between the results of the "Friction-Transfer" test with the compressive strength of M1 and M2 mortars.

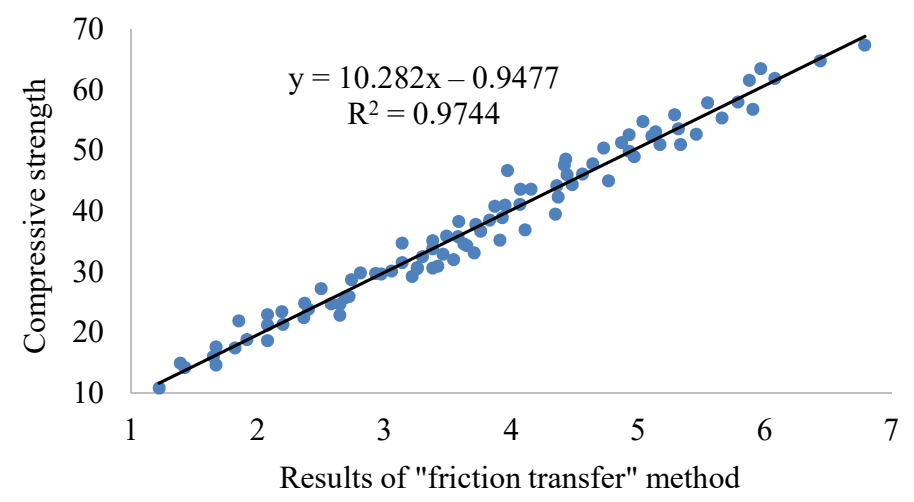

Fig. 7. Correlation between compressive strength of repair mortar and results of "Friction-Transfer" test (MPa)

Considering Fig. 7 it can be seen that there is a high correlation between the results of the "Friction-Transfer" test and the compressive strength of the repair mortars. So that the results of "Friction-Transfer" test with compressive strength of repair mortar have a correlation coefficient of $98.6 \%$ and determination coefficient of $97.4 \%$. Due to the high correlation coefficient between the compressive strength of the repair mortar and the results of the above method, it is easy to determine the compressive strength of the mortar using the "Friction-Transfer" test.

Fig. 8 shows the correlation between the results of the "Pull-off" test with the compressive strength of M1 and M2 mortars.

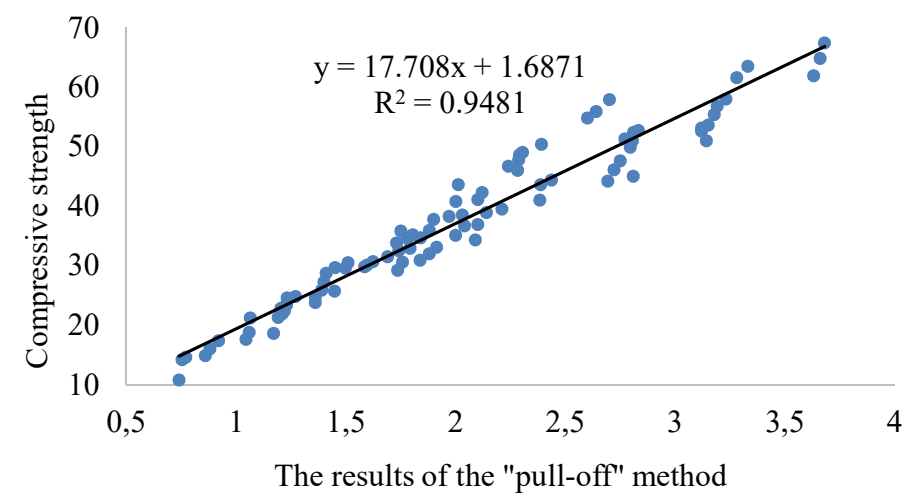

Fig. 8. Correlation between compressive strength of repair mortar and results of Pull-off Test (MPa)

Considering Fig. 8, it can be seen that there is a high correlation between the results of the "Pull-off" test and the compressive strength of the repair mortars. So that the results of "Pull-off test" with compressive strength of mortar have coefficients of determination and correlation was $94.8 \%$ and $97.3 \%$, respectively. Due to the high correlation coefficient between the compressive strength of the repair mortar and the results of the above method, it is easy to determine the compressive strength of the mortar by using the "Pull-off" test. 


\section{2. Flexural strength of repair mortar}

This section examines the flexural strength of repair mortars at ages 3, 7, 28, 42, and 90 days, which were subjected to in-water processed with release and release materials until testing. The results of the "Friction-Transfer" and "Pull-off" tests with M1 mortar tensile strength are shown in Table 6. In this table, the results of flexural strength, "Friction-Transfer" and "Pull-off" are averaged over the three tests, Table 6.

Table 6

Results of flexural strength, "Friction-Transfer" and "Pull-off" tests on M1 mortar (MPa)

\begin{tabular}{|c|c|c|c|c|c|c|c|c|c|c|c|c|c|c|c|}
\hline \multirow[b]{2}{*}{$\begin{array}{c}\text { Test } \\
\text { Method }\end{array}$} & \multicolumn{3}{|c|}{3 days } & \multicolumn{3}{|c|}{7 days } & \multicolumn{3}{|c|}{28 days } & \multicolumn{3}{|c|}{42 days } & \multicolumn{3}{|c|}{90 days } \\
\hline & 离 & $\stackrel{0}{\Xi}$ & 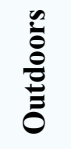 & है & 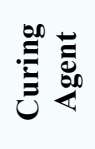 & $\frac{0}{\tilde{\Xi}}$ & हो & 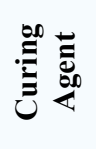 & 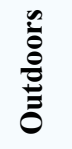 & होँ & 范 & 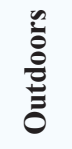 & हो & 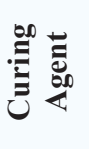 & 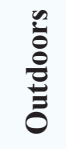 \\
\hline Flexural strength & 7.82 & 7.36 & 5.87 & 10.12 & 9.89 & 7.48 & 11.04 & 10.48 & 8.05 & 11.5 & 10.81 & 8.74 & 12.08 & 11.5 & 9.09 \\
\hline "Friction transfer" & 2.72 & 2.14 & 1.62 & 4.09 & 3.45 & 2.61 & 5.29 & 4.38 & 3.37 & 5.89 & 4.8 & 3.75 & 6.43 & 5.13 & 3.98 \\
\hline "Pull-off" & 1.42 & 1.24 & 0.89 & 2.08 & 1.87 & 1.37 & 2.65 & 2.31 & 1.72 & 3.28 & 2.78 & 2.05 & 3.65 & 3.13 & 2.15 \\
\hline
\end{tabular}

According to Table 6 for M1 mortar it is observed that the flexural strength of mortars processed with water is higher than those released in the outdoor. This is due to the completion of the cement hydration process inside the mortar to prevent moisture from escaping inside the mortar. For the mortars processed with water and with the materials processed with the mortars released in the outdoor, the 90-day flexural strength was 1.33 and 1.27 times, respectively. The same trend is observed for other ages, such that for water processed samples, the tensile strength values of 3, 7, 28 and 42 days are 1.33, 1.35, 1.37 and 1.31 times, respectively. Tensile strength of mortar released in outdoor. For the samples processed with the active substances, the tensile strength of the outdoor specimens in the above ages was $1.25,1.32,1.3$ and 1.24 , respectively. The results of the "Friction-Transfer" and "Pull-off" tests on the processed specimens have also increased over time.

The results of the "Friction-Transfer" and "Pull-off" tests with the flexural strength of M2 mortar can be seen in Table 7. In this table, the results of flexural strength, "Friction-Transfer" and "Pull-off" are averaged of 3 tests each.

Table 7

Results of Flexural strength, "Friction-Transfer" and "Pull-off" tests on M2 mortar (MPa)

\begin{tabular}{|c|c|c|c|c|c|c|c|c|c|c|c|c|c|c|c|}
\hline \multirow[b]{2}{*}{$\begin{array}{c}\text { Test } \\
\text { Method }\end{array}$} & \multicolumn{3}{|c|}{3 days } & \multicolumn{3}{|c|}{7 days } & \multicolumn{3}{|c|}{28 days } & \multicolumn{3}{|c|}{42 days } & \multicolumn{3}{|c|}{90 days } \\
\hline & 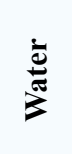 & $\stackrel{0}{\Xi}$ & 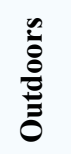 & $\frac{\bar{\Xi}}{3}$ & 葛 & 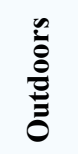 & 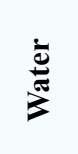 & $\stackrel{0}{\Xi}$ & $\frac{\stackrel{0}{0}}{\stackrel{0}{0}}$ & $\frac{\grave{E}}{\sum^{ \pm}}$ & 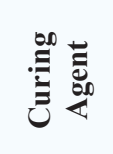 & $\frac{0}{\stackrel{0}{0}}$ & 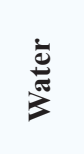 & $\stackrel{0}{\Xi}$ & $\frac{0}{\grave{0}}$ \\
\hline Flexural strength & 6.7 & 6.22 & 4.9 & 8.6 & 8.42 & 6.25 & 9.23 & 8.92 & 6.86 & 9.71 & 9.31 & 7.4 & 10.11 & 9.9 & 7.74 \\
\hline "Friction transfer" & 2.36 & 1.89 & 1.44 & 3.61 & 3.05 & 2.31 & 4.69 & 3.84 & 2.97 & 5.19 & 4.2 & 3.35 & 5.64 & 4.56 & 3.55 \\
\hline "Pull-off" & 1.22 & 1.06 & 0.76 & 1.77 & 1.61 & 1.19 & 2.29 & 1.99 & 1.49 & 2.82 & 2.4 & 1.76 & 3.17 & 2.74 & 1.88 \\
\hline
\end{tabular}

According to Table 7 for M2 mortars, it is observed that the flexural strength of mortars processed with water is higher than the mortars released in the outdoor. For the mortars processed with water and with the materials processed with the mortars released in the outdoor, the 90-day flexural strength was 1.31 and 1.28 times, respectively. The same trend is observed for other ages, such that for water processed samples, the tensile strength values of 3, 7, 28 and 42 days are 1.37, $1.38,1.34$ and 1.31, respectively. Tensile strength of mortar released in outdoor. For the samples processed with the active ingredients, the tensile strength of the outdoor specimens in the above ages was 1.27, 1.35, 1.3 and 1.26, respectively. The results of the "Friction-Transfer" and "Pull-off" 
tests on the processed specimens have also increased over time. In another study on the flexural strength of mortars, it was found that the 28-day flexural strength of the specimen was about $7 \%$ higher than the flexural strength of the 7-day specimen processed with water [21]. In this study, the ratio of bending strength of 28 -day to 7 -day samples processed with water increased about $7.5 \%$.

Fig. 9 shows the correlation between the results of the "Friction-Transfer" test with the flexural strength of M1 and M2 mortars.

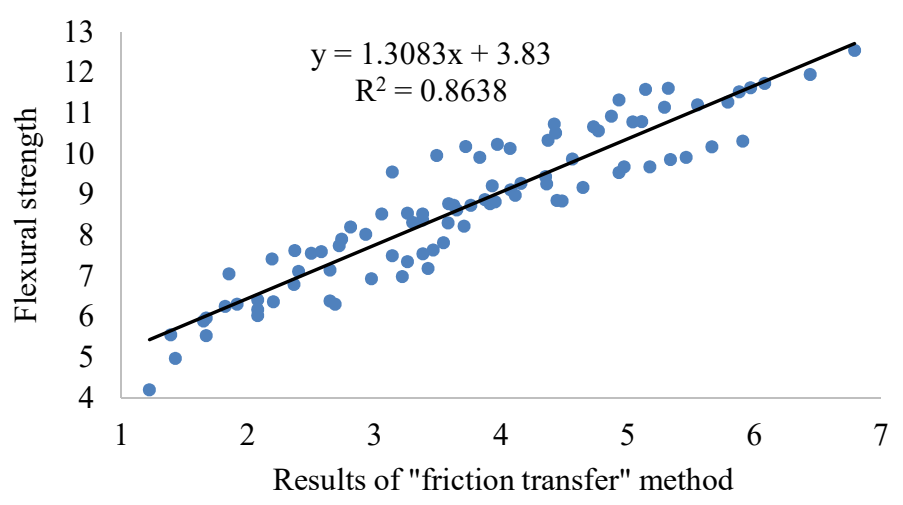

Fig. 9. Correlation between flexural strength of repair mortar and results of "Friction-Transfer" test (MPa)

Considering Fig. 9 it can be seen that there is a high correlation between the results of the "Friction-Transfer" test and the flexural strength of the repair mortars. Such a way that the results of "Friction-Transfer" test with tensile strength of repair mortar have a correlation coefficient of $93 \%$ and determination coefficient of $86.4 \%$. Due to the high correlation coefficient between the flexural strength of the repair mortar and the results of the above method, it is easy to determine the flexural strength of the mortar using the "Friction-Transfer" test.

Fig. 10 shows the correlation between the results of the "Pull-off" test with the flexural strength of M1 and M2 mortars.

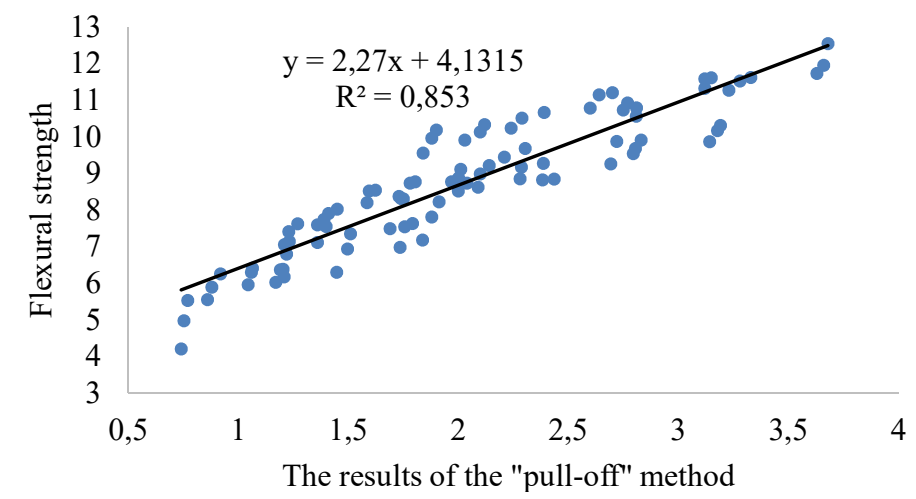

Fig. 10. Correlation between flexural strength of repair mortar and results of Pull-off Test (MPa)

Considering Fig. 10 it can be seen that there is a high correlation between the results of the "Pull-off" test and the flexural strength of the repair mortars. Such a way that the results of the "Pull-off" test with the flexural strength of the repair mortar have a correlation coefficient of $92.3 \%$ and a coefficient of determination of $85.3 \%$. Due to the high correlation coefficient between the flexural strength of the repair mortar and the results of the above method, it is easy to determine the flexural strength of the mortar by using the "Pull-off" test.

\section{3. Tensile strength of repair mortar}

In this section, the compressive strength of repair mortars at ages 3, 7, 28, 42, and 90 days, which were subjected to in-water processed, with release and release materials, were tested. The 
results of the "Friction-Transfer" and "Pull-off" tests with M1 mortar tensile strength are shown in Table 8. In this table the results of Pull-off, "Friction-Transfer" and "Pull-off" are averaged of 3 tests.

Table 8

Results of tensile strength, "Friction-Transfer" and "Pull-off" tests on M1 mortar (MPa)

\begin{tabular}{|c|c|c|c|c|c|c|c|c|c|c|c|c|c|c|c|}
\hline \multirow[b]{2}{*}{$\begin{array}{c}\text { Test } \\
\text { Method }\end{array}$} & \multicolumn{3}{|c|}{3 days } & \multicolumn{3}{|c|}{7 days } & \multicolumn{3}{|c|}{28 days } & \multicolumn{3}{|c|}{42 days } & \multicolumn{3}{|c|}{90 days } \\
\hline & हो & 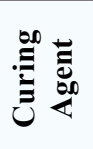 & 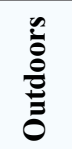 & है & 先 & 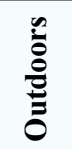 & 㐫 & 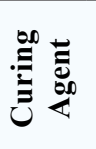 & $\frac{\mathscr{a}}{\grave{0}}$ & $\frac{\bar{\varpi}}{\bar{\pi}}$ & 兽 & 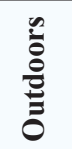 & 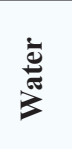 & 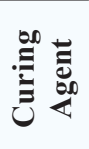 & 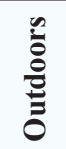 \\
\hline Tensile strength & 2.35 & 1.9 & 1.14 & 3.45 & 2.92 & 1.83 & 4.64 & 3.79 & 2.28 & 4.87 & 3.97 & 2.45 & 5.44 & 4.37 & 2.79 \\
\hline "Friction transfer" & 2.72 & 2.14 & 1.62 & 4.09 & 3.45 & 2.61 & 5.29 & 4.38 & 3.37 & 5.89 & 4.8 & 3.75 & 6.43 & 5.13 & 3.98 \\
\hline "Pull-off" & 1.42 & 1.24 & 0.89 & 2.08 & 1.87 & 1.37 & 2.65 & 2.31 & 1.72 & 3.28 & 2.78 & 2.05 & 3.65 & 3.13 & 2.15 \\
\hline
\end{tabular}

According to Table 8 for M1 mortar it is observed that the tensile strength of mortars processed in water and with handling materials is higher than those released in outdoor. This is due to the completion of the cement hydration process inside the mortar to prevent moisture from escaping inside the mortar. For mortars processed with water and with handling materials for mortars released in outdoor, the 90-day tensile strength was 1.95 and 1.57 times, respectively. The same is true for other ages, such a way that for water processed samples, the tensile strength values of $3,7,28$, and 42 days were $2.06,1.89,2.24$, and 1.99 times the tensile strength of the mortar released in the outdoor, respectively. For the specimens processed with the active substances, the tensile strength of the specimens processed with the outdoor specimens was 1.67, 1.59, 1.66, and 1.62, respectively. The results of the "Friction-Transfer" and "direct traction" tests on the processed specimens have also increased over time.

The results of the "Friction-Transfer" and "Pull-off" tests with M2 mortar tensile strength are shown in Table 9. In this table the results of tensile strength, "Friction-Transfer" and "Pull-off" are averaged of 3 tests.

Table 9

Results of the Tensile Strength, "Friction Transmission" and "Pull-off" tests on M2 mortar (MPa)

\begin{tabular}{|c|c|c|c|c|c|c|c|c|c|c|c|c|c|c|c|}
\hline \multirow[b]{2}{*}{$\begin{array}{c}\text { Test } \\
\text { Method }\end{array}$} & \multicolumn{3}{|c|}{3 days } & \multicolumn{3}{|c|}{7 days } & \multicolumn{3}{|c|}{28 days } & \multicolumn{3}{|c|}{42 days } & \multicolumn{3}{|c|}{90 days } \\
\hline & i⿱亠凶禸 & 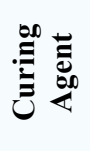 & 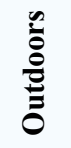 & ऐo & $\underset{U}{:}$ & 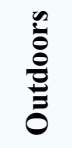 & हो & $\stackrel{0}{.0}$ & 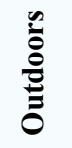 & 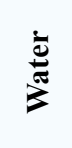 & 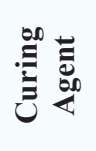 & 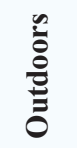 & D্ & $\stackrel{0}{\Xi}$ & $\frac{n}{\grave{\Xi}}$ \\
\hline Tensile strength & 1.91 & 1.56 & 0.92 & 2.82 & 2.35 & 1.49 & 3.74 & 3.07 & 1.87 & 3.92 & 3.17 & 2.04 & 4.45 & 3.55 & 2.27 \\
\hline "Friction transfer" & 2.36 & 1.89 & 1.44 & 3.61 & 3.05 & 2.31 & 4.69 & 3.84 & 2.97 & 5.19 & 4.2 & 3.35 & 5.64 & 4.56 & 3.55 \\
\hline “Pull-off" & 1.22 & 1.06 & 0.76 & 1.77 & 1.61 & 1.19 & 2.29 & 1.99 & 1.49 & 2.82 & 2.4 & 1.76 & 3.17 & 2.74 & 1.88 \\
\hline
\end{tabular}

According to Table 9 for M2 mortar it is observed that the tensile strength of mortars processed in water and with handling materials is higher than those released in outdoor. For the mortars processed with water and with the materials processed with the mortars released in the outdoor, the 90-day tensile strength was 1.96 and 1.56 times, respectively. The same is true for other ages, so that for water processed samples, the tensile strength values of 3, 7, 28 and 42 days were $2.28,1.89,2$, and 1.92 times the tensile strength of the mortar released in the outdoor, respectively. For the samples processed with the active ingredients, the tensile strengths of the specimens processed with the outdoor materials were 1.56, 1.55, 1.64 and 1.58, respectively. The results of the "Friction-Transfer" and "Pull-off" tests on the treated specimens have also increased over time. 
It can be seen that there is a high correlation between the results of the "Friction-Transfer" test and the tensile strength of the repair mortars (Fig. 11).

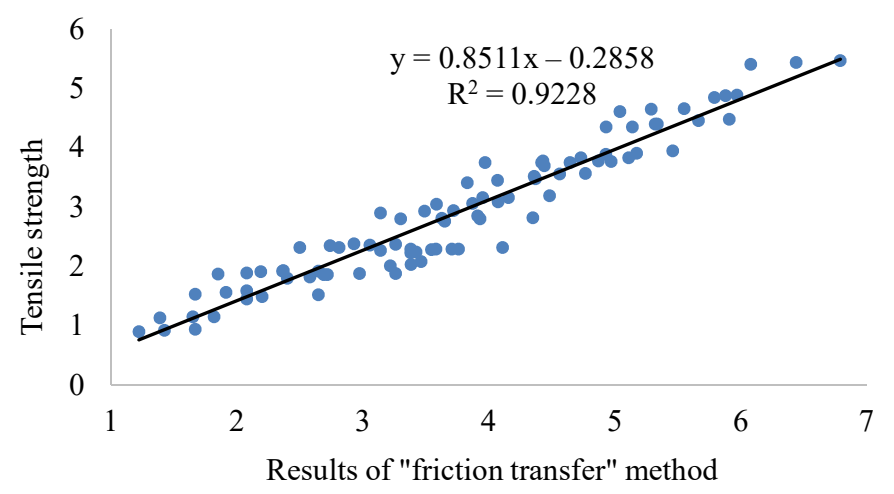

Fig. 11. Correlation between the results of the "Friction-Transfer" test with the tensile strength of M1 and M2 mortars

Such a way that the results of "Friction-Transfer" test with tensile strength of repair mortar have a correlation coefficient of $96 \%$ and determination coefficient of $92.2 \%$. Due to the high correlation coefficient between the tensile strength of the repair mortar and the results of the above method, it is easy to determine the tensile strength of the mortar using the "Friction-Transfer" test.

Fig. 12 shows the correlation between the results of the "Pull-off" test with the tensile strength of M1 and M2 mortars.

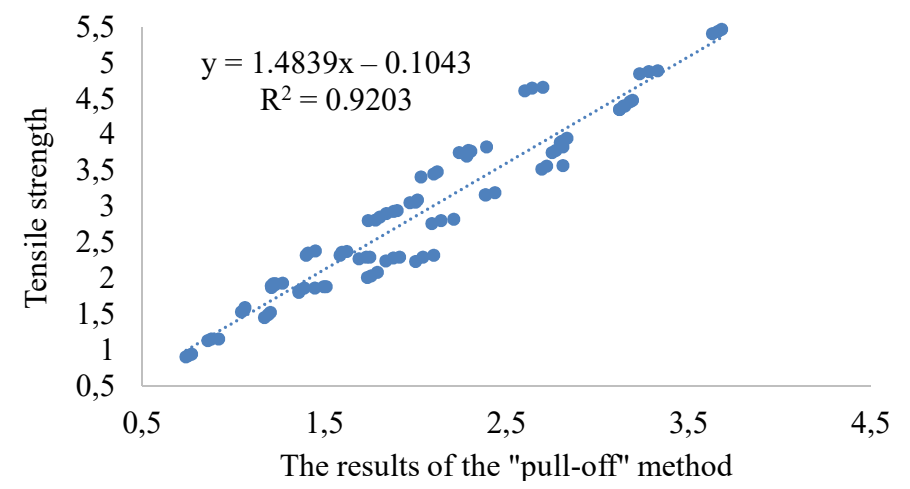

Fig. 12. Correlation between the tensile strength of the repair mortar and the results of the "Pull-off" Test (MPa)

Considering Fig. 12, it can be seen that there is a high correlation between the results of the "Pull-off" test and the tensile strength of the repair mortars, so that the results of the "Pull-off" test with tensile strength of repair mortar have a correlation coefficient of $95.9 \%$ and a coefficient of determination of $92 \%$. Due to the high correlation coefficient between the tensile strength of the repair mortar and the results of the above method, it is easy to determine the tensile strength of the mortar using the "Pull-off" test.

\section{4. The effect of water to cement ratio on mortar strength}

Table 10 compares the results of compressive, flexural and tensile strengths of the mortars, The compressive, flexural and tensile strength of M1 mortar are, on average, 1.19, 1.23 and 1.17 times the M2 mortar strength, respectively, because M1 mortar has a lower water/cement ratio. For M2 mortar due to the large amount of water in the mix, some water remains when the concrete hardens, this confined water gradually vaporizes and leaves empty spaces, the presence of these holes reducing the strength of the concrete. But in M1 mortar, due to the low water-to-cement ratio, almost all water is consumed during the hydration reaction, so water 
does not evaporate and the number of cavities decreases and does not decrease the strength of the concrete. The water to cement ratio has a direct relationship with the amount of cavities and their diameter inside the concrete and its increase reduces the compressive strength of the concrete. In general, according to Abram's law, the strength of cementations materials is inversely proportional to the ratio of water to cement, assuming full compaction at a given age and ordinary temperature [22].

Hydration of cement is the result of chemical reaction between the molecules of the main components of cement and water. The main reactions between silicates in cement, $\mathrm{C}_{3} \mathrm{~S}$ and $\mathrm{C}_{2} \mathrm{~S}$, with water (abbreviated $\mathrm{H}$ ) are as follows.

$$
\begin{aligned}
& 2 \mathrm{C}_{3} \mathrm{~S}+6 \mathrm{H} \longrightarrow \mathrm{C}-\mathrm{S}-\mathrm{H}+3 \mathrm{CH} \\
& 2 \mathrm{C}_{2} \mathrm{H}+4 \mathrm{H} \longrightarrow \mathrm{C}-\mathrm{S}-\mathrm{H}+\mathrm{CH}
\end{aligned}
$$

The hydration products based on the above relationships are calcium silicate hydrate and calcium hydroxide. C-S-H is actually $\mathrm{C}_{3} \mathrm{~S}_{2} \mathrm{H}_{3}$ with $\mathrm{C}, \mathrm{S}$ and $\mathrm{H}$ representing $\mathrm{CaO}, \mathrm{SiO}_{2}$ and $\mathrm{H}_{2} \mathrm{O}$, respectively. Also the $\mathrm{CH}$ compound is actually $\mathrm{Ca}(\mathrm{OH})_{2}$. Calcium silicate hydrate, $\mathrm{C}-\mathrm{S}-\mathrm{H}$, is a high-strength solid compound so that the compressive strength of the hardened mortar is mainly due to the $\mathrm{C}-\mathrm{S}-\mathrm{H}$ compound. $\mathrm{C}_{3} \mathrm{~S}$ along with water rapidly enters chemical reactions and hardens mortars; so much of the resistance gained in the early days of its life was due to the chemical composition of water with $\mathrm{C}_{3} \mathrm{~S}$. Resistance after age 7 is more due to $\mathrm{C}_{2} \mathrm{~S}$ reaction with water. Lack of moisture protection for the mortar causes a considerable part of the chemical reactions of the water and cement to fail and the mortar does not achieve the expected toughness and hardness. Incomplete and inadequate handling, the compressive, tensile and flexural strength of the hardened mortar will be reduced.

In Fig. 13, photos taken from the mortar cured in water using scanning electron microscope is shown. It can be seen from Fig. 13 that by maintaining the moisture content of the mortar by proper treatment, cracks inside the mortar are prevented, which reduces the mortar resistance.

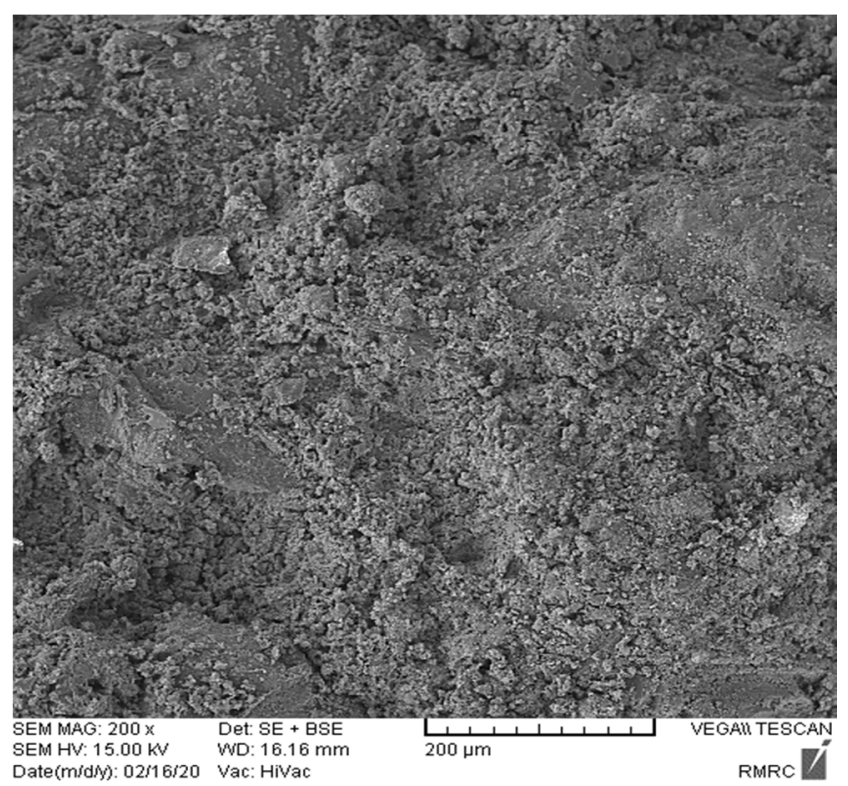

Fig. 13. The result of scanning electron microscopy performed on the mortar

Fig. 14 shows photos taken of mortar released in open space using scanning electron microscopy. It can be seen from Fig. 14 that lack of moisture retention inside the mortar causes cracking and empty and empty space, which causes the mortar resistance to decrease. 


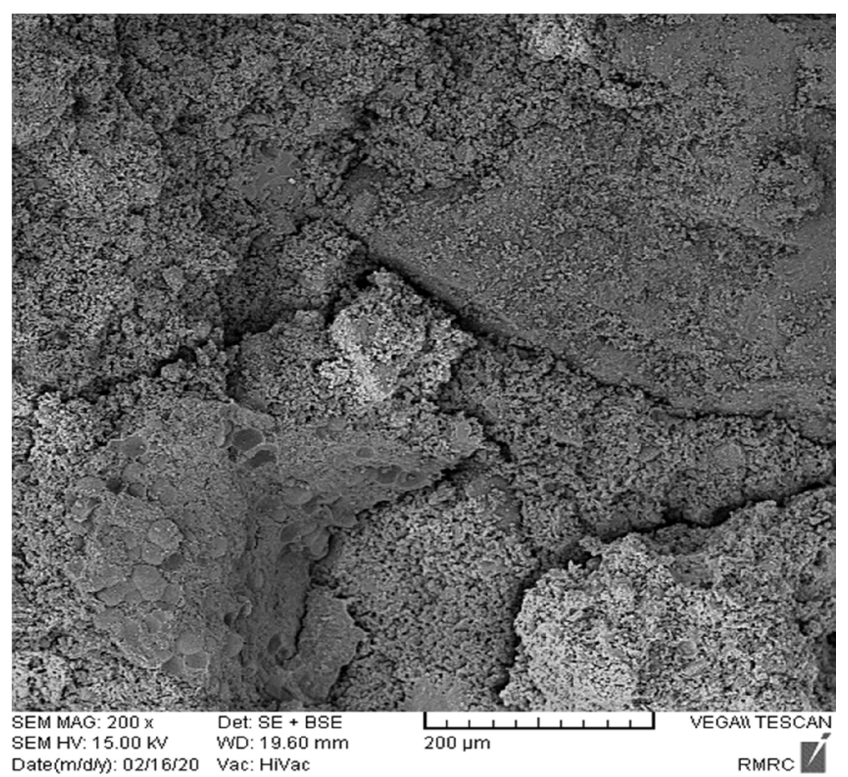

Fig. 14. Scanning electron microscopy results on mortar released in open space

The ratio of tensile and flexural strength of repair mortars to their compressive strength.

Table 10 shows the ratio of tensile and flexural strength of repair mortars to their compressive strength.

Table 10

Ratio of tensile and flexural strength of repair mortars to compressive strength

\begin{tabular}{|c|c|c|c|c|c|c|c|c|c|c|c|c|c|c|c|c|}
\hline & & \multicolumn{3}{|c|}{3 days } & \multicolumn{3}{|c|}{7 days } & \multicolumn{3}{|c|}{28 days } & \multicolumn{3}{|c|}{42 days } & \multicolumn{3}{|c|}{90 days } \\
\hline & & हो & 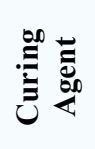 & 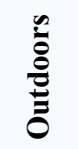 & $\sum^{\grave{ \pm}}$ & 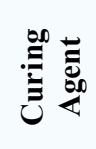 & 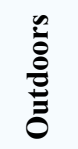 & 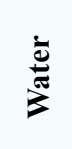 & $\stackrel{0}{:}$ & $\frac{n}{\stackrel{0}{0}}$ & ì & 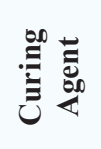 & $\begin{array}{l}0 \\
\frac{0}{0} \\
\stackrel{0}{0}\end{array}$ & $\sum_{\bar{\omega}}^{\bar{\pi}}$ & $\stackrel{0}{:}$ & 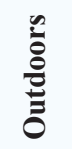 \\
\hline \multirow{2}{*}{$\begin{array}{l}\text { Tensile to } \\
\text { compressive }\end{array}$} & M1 & 8.2 & 8.1 & 7.2 & 8.5 & 8 & 7.4 & 8.3 & 7.7 & 6.8 & 7.9 & 7.8 & 6.7 & 8.4 & 8.2 & 7.4 \\
\hline & M2 & 8.1 & 8.1 & 6.9 & 8.3 & 7.8 & 7.1 & 7.8 & 7.5 & 6.5 & 7.6 & 7.3 & 6.6 & 8.2 & 7.9 & 7 \\
\hline \multirow{2}{*}{$\begin{array}{l}\text { Flexural to } \\
\text { pressure }\end{array}$} & M1 & 27.4 & 31.4 & 36.4 & 24.9 & 27.4 & 30.1 & 19.6 & 21.5 & 23.9 & 18.8 & 21.4 & 24.1 & $81 / 7$ & 21.7 & 24.2 \\
\hline & M2 & 28.7 & 32.3 & 37.1 & 25.2 & 27.8 & 29.9 & 19.4 & 21.8 & 23.9 & 19 & 21.7 & 24 & 19 & 22 & 24.2 \\
\hline
\end{tabular}

Table 10 shows that the average tensile strength is about $7.64 \%$ of mortar compressive strength and the ratio of flexural strength to compressive strength is $24.9 \%$. In another study on tensile strength of mortars it was found that the ratio of tensile strength of mortar to compressive strength is $7 \%$.

\section{Discussion of results}

Summarizing the results presented in Section 3, it can be concluded that there is a high linear correlation between the results of the readings obtained from the "friction transfer" and "pull-off" tests with the laboratory results. Since standard compressive, tensile and flexural tests are the major method for determining the strength of materials; therefore, it was attempted in this section to compare the results of the above tests to obtain the equivalent strength of cementations mortars from the results of the tests of "friction transfer" and "pull-off". Standard compressive, tensile and flexural tests have shown the mortar resistance in certain conditions and it may not be due to factors such as disregard for the method of operation, the actual conditions of the structure, How to select samples from the entire collection, variations in the type and amount of materials from one module to another, and differences in compaction rates, differences in 
mortar storage temperature and moisture content, the characteristics and properties of the mortar used in the different parts. Fig. 7-12 show that; the correlation coefficient between the results of standard laboratory tests and semi-destructive tests is $92 \%$ and "friction transfer" and "pulloff" respectively, this demonstrates the high accuracy of these tests for evaluating the strength of materials such as mortar and concrete performed at the site and at different ages. In addition to evaluating the application of the "friction transfer" method in determining the strength of cementations mortars, results were presented such as the effect of different techniques on mortar strength and the relationship between tensile and flexural strength and compressive strength of cementations mortars. Scanning electron microscopy showed that inactivity causes continuous cracks in the mortar, which reduces its resistance.

\section{Conclusion}

In this study, the "friction transfer" test was used to evaluate the strength of cement mortars at different ages under different operating conditions. Therefore, the relationship between the "pull-off" test and the standard compression, bending and tensile tests with the "friction transfer" test was investigated. The results are as follows:

Due to the high correlation coefficient between compressive, flexural and flexural strengths of mortars, The results of the "Friction-Transfer" and "Pull-off" tests can easily and in situ determine the mortar strengths using the above methods.

The correlation coefficient between compressive, flexural and tensile strength of mortars and the results of "Friction-Transfer" test were 98.6, 93 and 96, respectively.

Correlation coefficients between compressive, flexural and tensile strength of mortars and the results of "Pull-off test" were 97.3, 92.3 and 95.9, respectively.

The treatment of mortars with water and handling agents showed that this increases the readings obtained from the "Friction-Transfer" and "Pull-off" tests and the compressive, flexural and tensile strengths of the mortars compared to the samples released in the open space.

The water-to-cement ratio has an inverse relationship with the strengths of the tests performed on mortar so that increasing the water-to-cement ratio has reduced the resulting strengths.

The tensile and flexural strength of mortars are $7.64 \%$ and $24.9 \%$ of their compressive strength, respectively.

\section{References}

[1] ASTM C42/C42M-18a. Standard Test Method for Obtaining and Testing Drilled Cores and Sawed Beams of Concrete (2018). ASTM International. doi: http://doi.org/10.1520/C0042_C0042M-18A

[2] Masi, A., Digrisolo, A., Santarsiero, G. (2013). Experimental Evaluation of Drilling Damage on the Strength of Cores Extracted from RC Buildings. World Academy of Science, Engineering and Technology International Journal of Structural and Construction Engineering, 7 (7), 525-531.

[3] ASTM C900-15. Standard Test Method for Pullout Strength of Hardened Concrete (2015). ASTM International, West Conshohocken, PA. doi: http://doi.org/10.1520/C0900-15

[4] ASTM C597-16. Standard Test Method for Pulse Velocity through Concrete (2016). ASTM International, West Conshohocken, PA. doi: http://doi.org/10.1520/C0597-16

[5] ASTM C808/C805M-18. Standard Test Method for Rebound Number of Hardened Concrete (2018). ASTM International, West Conshohocken, PA. doi: http://doi.org/10.1520/C0805_C0805M-18

[6] Naderi, M. (2005). Friction-transfer test for the assessment of in situ strength and adhesion of cementitious materials. Construction and Building Materials, 19 (6), 454-459. doi: https://doi.org/10.1016/j.conbuildmat.2004.07.018

[7] ASTM C1583-04. Standard test method for tensile strength of concrete surfaces and the bond strength or tensile strength of concrete repair and overlay materials by direct tension (Pull-off method) (2004). ASTM International, West Conshohocken, PA. doi: http://doi.org/10.1520/C1583-04

[8] Naderi, M. (2011). Non-Destructive Evaluation of Engineering Properties of Intact Rock Using the Friction-Transfer Method. Arabian Journal for Science and Engineering, 36 (2), 215-226. doi: https://doi.org/10.1007/s13369-010-0021-9

[9] Eskandari-Naddaf, H., Kazemi, R. (2018). Experimental evaluation of the effect of mix design ratios on compressive strength of cement mortars containing cement strength class 42.5 and 52.5 MPa. Procedia Manufacturing, 22, 392-398. doi: https:// doi.org/10.1016/j.promfg.2018.03.060 
[10] Still, G. T. (2004). Strength of cementitious mortars: a literature review with special reference to weak mortars in tension. United Kingdom, University of Warwick, Coventry, CV4 7AL.

[11] Kim, Y.-Y., Lee, K.-M., Bang, J.-W., Kwon, S.-J. (2014). Effect of W/C Ratio on Durability and Porosity in Cement Mortar with Constant Cement Amount. Advances in Materials Science and Engineering, 2014, 1-11. doi: https://doi.org/10.1155/2014/273460

[12] Mannan, M. A., Basri, H. B., Zain, M. F. M., Islam, M. N. (2002). Effect of curing conditions on the properties of OPSconcrete. Building and Environment, 37 (11), 1167-1171. doi: https://doi.org/10.1016/s0360-1323(01)00078-6

[13] Neville, A. M. (1992). Properties of concrete. USA: Longman Scientific and Technical.

[14] ASTM C136-01. Standard Test Method for Sieve Analysis of Fine and Coarse Aggregates (2001). ASTM International, West Conshohocken, PA. doi: http://doi.org/10.1520/C0136-01

[15] ASTM C127-15. Standard test method for relative density (specific gravity) and absorption of coarse aggregate (2015). ASTM International, West Conshohocken, PA. doi: http://doi.org/10.1520/C0127-15

[16] ASTM C127-12. Standard Test Method for Density, Relative Density (Specific Gravity), and Absorption of Coarse Aggregate. ASTM International, West Conshohocken, PA. doi: http://doi.org/10.1520/C0127-12

[17] ASTM C348-19. Standard test method for Flexural Strength of Hydraulic-Cement Mortars (2019). ASTM International, West Conshohocken, PA. doi: http://doi.org/10.1520/C0348-19

[18] ASTM C190. Method of Test for Tensile Strength of Hydraulic Cement Mortars (Withdrawn 1990) (1985). American Society for Testing and Materials.

[19] ASTM C109/C109M-13. Standard Test Method for Compressive Strength of Hydraulic Cement Mortars (Using 2-in. or [50-mm] Cube Specimens) (2013). ASTM International, West Conshohocken, PA. doi: http://doi.org/10.1520/C0109_C0109M-13

[20] Han, V., Ros, S., Shima, H. (2013). Effects of Sand Content, Superplasticizer Dosage, and Mixing Time on Compressive Strength of Mortar. ACI Materials Journal, 110 (1). doi: https://doi.org/10.14359/51684363

[21] Çakır, Ö., Aköz, F. (2008). Effect of curing conditions on the mortars with and without GGBFS. Construction and Building Materials, 22 (3), 308-314. doi: https://doi.org/10.1016/j.conbuildmat.2006.08.013

[22] Neville, A. M., Brooks, J. J. (2015). Concrete technology. Pearson Education Canada, 464.

Received date 03.02.2020

Accepted date 23.03.2020

Published date 31.03.2020
(C) The Author(s) 2020

This is an open access article under the CC BY license (http://creativecommons.org/licenses/by/4.0). 